\title{
Ensuring the policy relevance of population health research: experiences from the Drug Policy Modelling Program
}

\author{
Alison Ritter \\ National Drug and Alcohol Research Centre, \\ The University of New South Wales \\ Email: alison.ritter@unsw.edu.au
}

\begin{abstract}
Illicit drugs are an important public health concern. A unique approach to tackling this problem is represented in the work of the Drug Policy Modelling Program which aims to improve evidence-informed policy by reducing the gap between research and policy. There are three elements to the Drug Policy Modelling Program: generating new knowledge; translating evidence into information of relevance for decision makers; and studying policy processes. Key aspects include the use of computer modelling as a translational tool and the focus on understanding policy processes such as the role of media and politics, important in contextualising the research-policy nexus. Other features of the Drug Policy Modelling Program approach include engagement of diverse disciplines, and government researcher partnerships.
\end{abstract}

information of relevance for decision makers; and (3) studying policy processes. While many Australian researchers engage independently in each of these activities (although largely focused on the first of the three), the Drug Policy Modelling Program sees all three elements as essential to achieve evidence-informed policy. Additionally, the integration and combination of the three elements is required. ${ }^{5}$ While translation of research evidence into policy has been an important recent focus of health research, the majority of the work has concentrated on improving the dissemination of research ${ }^{6}$ and providing support to policy makers to improve their uptake of research evidence. ${ }^{7}$ The Drug Policy Modelling Program supersedes these traditional foci - it is neither dissemination nor uptake alone, but addresses applied research questions of relevance to decision makers, integrates new research evidence with research on public policy and political processes, and develops alternate methodologies to translate evidence.

This paper describes the three elements of the Drug Policy Modelling Program and provides brief examples of the work. Achieving change in policy can take many years, with 17 years cited as an average. ${ }^{8}$ The Drug Policy Modelling Program (the Program) is less than 10 years old and hence a full assessment of its impact on policy is premature. Nonetheless, the principles and examples of work provided herein highlight the approach.

\section{The Drug Policy Modelling Program}

The Program has been sustained by a core funding grant from a philanthropic organisation (the Colonial Foundation Trust). This has been essential to achieving an applied/ practice research focus. Independence of funding from government is vital. In addition, the core funds are supplemented by traditional scientific funding from bodies such as the National Health and Medical Research Council. The Program combines both practical highly-applied research often conceived and conducted in collaboration with government (largely funded from the core funds or by government) with scholarly independent empirical research (largely funded from research bodies). Commissioned research such as project requests from government can be undertaken alongside investigator-driven research. This balance between commissioned and investigator-driven research is important to sustain a research workforce, to enable applied and more empirical work to co-exist, and to 
advance opportunities for mutual learning; commissioned research may also lead to an investigator-driven grant application and vice versa.

Despite a strong applied and practical focus - working with governments on problems and issues as they arise - the location of the Program within the National Drug and Alcohol Research Centre at the University of New South Wales (NSW) provides essential connection with scholarly endeavour. The risk of strongly applied, governmentfocused research is that it can reduce the opportunity and incentive to publish in peer-reviewed journals; the university auspice encourages peer-reviewed publication and ensures that work meets academic standards. In addition, to be regarded as 'expert' and called upon by governments to assist with policy decision making requires an established academic profile.

Another feature of the Program is the multidisciplinary nature of the team. It includes psychology, criminology, public health, epidemiology, economics, systems approaches, political science and health economics. Working across disciplines has a number of challenges, including different 'world views', methodological differences and mundane but important issues such as different disciplinary norms around authorship. Tackling a complex problem such as illicit drugs requires such a multidisciplinary approach. Most public health problems can no longer be seen as merely health issues: the environment, sociocultural influences, economics and regulation, for example, all provide insights into heath behaviours and new policy solutions. Additionally, there is also the law enforcement element for illicit drugs.

\section{The three elements of the Program Generating new knowledge}

Generation of new knowledge is critical but much research in the drug field is largely marginal to the interests of policy makers. For example, the majority of alcohol and tobacco research is descriptive epidemiology ${ }^{9}$ which, while important, does not readily translate to policy or funding options. The challenge is to conduct best practice science on research questions of relevance and meaning to decision makers, and to focus on gaps in knowledge. Within illicit drugs policy, the largest gap is in the evidence base for law enforcement. A comprehensive and systematic search revealed 167 studies published on drug law enforcement ${ }^{10}$ which compares poorly to the thousands of published papers on drug treatment.

In redressing this gap, the Program has concentrated on developing a better evidence base regarding the effectiveness of drug law enforcement interventions (Griffith University, Prof Lorraine Mazerolle). This work has included systematic reviews as well as experimental trials of drug law enforcement intervention. ${ }^{11-13}$ The Program has also seed funded the first cohort study of street-based injecting drug users (Burnet Institute, A/Prof Paul Dietze).

Strong collaboration with government is essential in bridging the divide between research and policy in the conduct of research. Collaborative research has been undertaken with a number of governments across Australia including the ACT Department of Health, NSW Department of Health, NSW Police and Australian Federal Police. These research projects have commenced with discussions and negotiations regarding important research questions and knowledge gaps. The identification of research questions in collaboration with government then leads to a negotiation regarding appropriate research methods and access to data. The final reports are then provided to government along with other types of dissemination, such as presentations and briefings.

\section{Translating research evidence}

There are many barriers to the adoption of research into the policy process. ${ }^{14-18}$ Proposed solutions have been extensively documented in the above references and in others. Rather than focus on dissemination per se, the Program has concentrated on the active translation from data or science into meaningful information that has value and is readily understood by decision makers. For example, statistical significance testing can be translated into the numbers needed to be treated to achieve a change in population outcomes. In the drug policy work, the primary translation tool of the Program has been computer modelling. Computer models are highly relevant tools for policy decision making because case studies in the real world are difficult; models, built on existing research, can explore policy options not yet implemented. Models can be effective and useful aids for decision-making processes because they represent the complex and dynamic relationships between important variables in the policy domain. ${ }^{19}$ The success of modelling, when used as a translational tool, requires effective collaboration between experts in the content domain and experts in modelling alongside effective relationships with governments willing and able to engage in the process.

The Program has used an array of different types of modelling, including system dynamics, agent-based modelling and mathematical modelling. For example, a mathematical model has been developed to explore the provision of hepatitis $\mathrm{C}$ treatment: whether it is preferable to provide hepatitis $\mathrm{C}$ treatment to those in existing drug treatment (such as methadone maintenance) or to existing injectors. ${ }^{20}$ Using system dynamics the Australian pharmacotherapy maintenance treatment system has been modelled to explore scenarios regarding treatment availability and patient co-payments. ${ }^{21}$ These models are not predictive in the sense of making projections into the future. They are simulations that provide the opportunity for decision 
makers to explore plausible scenarios. For example, the agent-based model simulates a street-based heroin market. $^{22-24}$ Building the model required the synthesis of existing research studies and data sources (such as court records) to describe the actions of injecting drug users, police and outreach workers within the simulation. Once built, the model was used to explore the impacts of changing police numbers, the type of policing strategy or the availability of treatment. In workshops with decision makers, the simulations allowed exploration of the intended and unintended effects of potential policy choices, such as increasing the number of police patrols. While a model does not provide a definitive solution for decision making, it provides opportunity to examine plausible policy impacts. In this way, it is a dialogue-based participatory process. Given that policy decisions are rarely driven by a single research outcome ${ }^{25}$ modelling fits nicely with thorough understanding of the policy process.

\section{Studying policy processes}

A policy decision, whether concerned with major reform or with incremental funding decisions, is a culmination point where multiple factors come together to determine the final outcome. These factors include the research evidence brought to bear but also political factors, perceived public opinion, and practicalities (such as resources). No policy process relies solely on research evidence and the rational consideration of options. For this reason, a comprehensive approach to evidence-based policy must include a focus on policy processes such as the politics and public opinion that can underlie a decision. Many theorists have written about policy processes. ${ }^{26,27}$ The application of this body of knowledge, largely from political science, to illicit drug policy in Australia is just commencing. ${ }^{28}$

Public opinion regarding illicit drugs is strong, and public opinion can have a substantial influence on policy decision making. ${ }^{29}$ Research that examines the role of public opinion can make an important contribution to understanding both the enablers and barriers to good policy in this domain. Within policy processes, research evidence is used in a myriad of ways. ${ }^{30}$ Studying the sources that policy makers use to access research evidence provides useful information for how researchers may better target their dissemination. ${ }^{31}$

Public forums where research evidence is debated and discussed, such as summits, can demonstrate the interplay between research and policy processes. ${ }^{32}$ In the illicit drugs area, drug summits have produced transformative policy; for example, the NSW Drug Summit resulted in the establishment of the injecting centre in Kings Cross. ${ }^{33}$ This demonstrates the powerful community and political processes that can shape public health policy. Community views, as represented by public opinion and political processes, play an integral role in policy processes; researchers need to be mindful of these processes in striving for evidence-informed policy.

\section{Conclusion}

Alcohol and drug harm is a pressing contemporary public health issue. The drug policy research program described herein aims to integrate three key elements: generating new evidence, which relies on knowledge about policy priorities and gaps; translating evidence through the use of computer modelling; and studying policy processes, including the role that public opinion, the media and political processes can play in determining illicit drug policy. Ultimately, we seek to enhance the uptake of research evidence in order to strengthen Australian alcohol and drug policy.

\section{Acknowledgments}

The DPMP is funded by the Colonial Foundation Trust. Alison Ritter is a recipient of a National Health and Medical Research Council Career Development Award. The DPMP Chief Investigators are: A/Prof Alison Ritter (UNSW), Prof Gabriele Bammer (ANU), Prof Lorraine Mazerolle (UQ), A/Prof Paul Dietze (Burnet Institute) and Pascal Perez (HEMA Consulting).

\section{References}

1. Collins DJ, Lapsley HM. The cost of tobacco, alcohol and illicit drug abuse to Australian society in 2004/05. National Drug Strategy Monograph Series No. 64. Commonwealth of Australia; 2008.

2. Hall W. The contribution of research to Australian policy responses to heroin dependence 1990-2001: a personal retrospection. Addiction 2004; 99(5): 560-9. doi:10.1111/ j.1360-0443.2004.00717.x

3. Fitzgerald J, Sewards T. Evidence-Based Practice in the Australian Drug Policy Community. In: Lin V, Gibson B, editors. Evidence-based health policy: problems and possibilities. Melbourne: Oxford University Press; 2003.

4. Agar M. How the drug field turned my beard grey. Int $J$ Drug Policy 2002; 13(4): 249-59. doi:10.1016/S0955-3959(02) 00122-6

5. Ritter A, Bammer G, Hamilton M, Mazerolle L. DPMP Team Effective drug policy: a new approach demonstrated in the Drug Policy Modelling Program. Drug Alcohol Rev 2007; 26(3): 265-71. doi:10.1080/09595230701247665

6. Lin V, Gibson B, editors. Evidence-based health policy: problems and possibilities. Melbourne: Oxford University Press; 2003.

7. Edwards M. Social science research and public policy: narrowing the divide. Aust J Public Administration 2005; 64(1): 68-74. doi:10.1111/j.1467-8500.2005.00417.x

8. Balas EA, Boren SA. Managing clinical knowledge for health care improvement. In: Bemmel J, McCray AT, editors. Yearbook of Medical Informatics 2000: Patient-Centered Systems. Stuttgart: Schattauer; 2000. pp. 65-70.

9. Sanson-Fisher RW, Campbell EM, Htun AT, Bailey LJ, Millar CJ. We are what we do: research outputs of public health. Am J Prev Med 2008; 35(4): 380-5. doi:10.1016/j.amepre.2008.06.039

10. Mazerolle L, Soole D, Rombouts S. Monograph No. 05. Drug law enforcement: The evidence. DPMP Monograph Series. Fitzroy: Turning Point Alcohol and Drug Centre; 2005. 
11. Mazerolle L, Soole D, Rombouts S. Street-level drug law enforcement: a meta-analytic review. J Exp Criminol 2006; 2(4): 409-35. doi:10.1007/s11292-006-9017-6

12. Mazerolle L, Soole D, Rombouts S. Drug law enforcement: a review of the evaluation literature. Police $Q 2007 ; 10(2)$ : 115-53. doi:10.1177/1098611106287776

13. Drew JM. Police responses to the methamphetamine problem: an analysis of the organizational and regulatory context. Police $Q$, in press.

14. Brownson RC, Royer C, Ewing R, McBride TD. Researchers and policymakers: travelers in parallel universes. Am J Prev Med 2006; 30(2): 164-72. doi:10.1016/j.amepre.2005.10.004

15. Crosswaite C, Curtice L. Disseminating research results - the challenge of bridging the gap between health research and health action. Health Promot Int 1994; 9(4): 289-96. doi:10.1093/ heapro/9.4.289

16. Hanney SR, Gonzalez-Block MA, Buxton MJ, Kogan M. The utilisation of health research in policy-making: concepts, examples and methods of assessment. Health Res Policy Syst 2003; 1(1): 2. doi:10.1186/1478-4505-1-2

17. Stone D, Maxwell S, Keating M. Bridging research and policy. UK Department for International Development, Radcliffe House, Warwick University: Warwick, UK; 2001. p. 50.

18. Weiss $\mathrm{CH}$, editor. Using social research in public policy making. Lexington, MA: Lexington Books; 1977.

19. Meadows DH, Robinson JM. The electronic oracle: computer models and social decisions. Syst Dyn Rev 2002; 18(2): 271-308. doi:10.1002/sdr.239

20. Zeiler I, Langlands T, Murray JM, Ritter A. Optimal targeting of Hepatitis $\mathrm{C}$ virus treatment among injecting drug users to those not enrolled in methadone maintenance programs. Drug Alcohol Depend 2010; 110(3): 228-33. doi:10.1016/ j.drugalcdep.2010.03.006

21. Chalmers J, Ritter A, Heffernan M, McDonnell G. Modelling pharmacotherapy maintenance in Australia: exploring affordability, availability, accessibility and quality using system dynamics. ANCD Research Paper \#19. Canberra: Australian National Council on Drugs; 2009.

22. Dray A, Mazerolle L, Perez P, Ritter A. Drug law enforcement in an agent-based model: simulating the disruption to street-level drug markets. In: Liu L, Eck J, editors. Artificial crime analysis systems: using computer simulations and geographic information systems. Hershey, PA: IGI Global; 2008. pp. $352-71$.

23. Dray A, Mazerolle L, Perez P, Ritter A. Policing Australia's 'heroin drought': using an agent-based model to simulate alternative outcomes. J Exp Criminol 2008; 4(3): 267-87. doi:10.1007/s11292-008-9057-1

24. Perez P, Dray A, Ritter A, Dietze P, Moore T, Mazerolle L. SimDrug: exploring the complexity of illicit drug markets. In: Perez P, Batten D, editors. Complex science for a complex world - Exploring human ecosystems with agents. Canberra: ANU E press; 2006. pp. 193-224.

25. Weiss CH, Murphy-Graham E, Birkeland S. An alternate route to policy influence: how evaluations affect D.A.R.E. Am J Eval 2005; 26(1): 12-30. doi:10.1177/1098214004273337

26. Kingdon T. Agendas, alternatives, and public policy. 2nd ed. New York: Longman; 2003.

27. Sabatier PA, editor. Theories of policy processes. Colorado: Westview Press; 2007.

28. Ritter A, Bammer G. Models of policy making and their relevance for drug research. Drug Alcohol Rev 2010; 29(4): 352-7. doi:10.1111/j.1465-3362.2009.00155.x

29. Matthew-Simmons F, Love S, Ritter A. Monograph 17: A review of Australian public opinion surveys on illicit drugs. DPMP Monograph Series. Sydney: National Drug and Alcohol Research Centre; 2008.

30. Weiss $\mathrm{CH}$. The many meanings of research utilization. Public Adm Rev 1979; 39: 426-31. doi:10.2307/3109916

31. Ritter A. How do drug policy makers access research evidence? Int J Drug Policy 2009; 20(1): 70-5. doi:10.1016/j.drugpo.2007. 11.017

32. Nathan SA, Develin E, Grove N, Zwi AB. An Australian childhood obesity summit: the role of data and evidence in 'public' policy making. Aust New Zealand Health Policy 2005; 2: 17. doi:10.1186/1743-8462-2-17

33. Van Beek I. In the eye of the needle: diary of a medically supervised injecting centre. Crows Nest: Allen \& Unwin; 2004 